\title{
ケトプロフェンテープ先発・後発医薬品の全身移行性の in vitro 放出試験による予測
}

\author{
阿波圭介, ${ }^{a}$ 佐藤宏樹, ${ }^{a}$ 堀 里子, ${ }^{a, b}$ 澤田康文*, $a$
}

\section{Prediction of Systemic Exposure of Ketoprofen Tapes by In Vitro Release Test and Pharmacokinetic Model Analysis: Comparison between Brand-name and Generic Formulations}

\author{
Keisuke Awa, ${ }^{a}$ Hiroki Satoh, ${ }^{a}$ Satoko Hori,${ }^{a, b}$ and Yasufumi Sawada ${ }^{*, a}$ \\ ${ }^{a}$ Graduate School of Pharmaceutical Sciences; and ${ }^{b}$ Interfaculty Initiative in Information Studies, \\ The University of Tokyo; 7-3-1 Hongo, Bunkyo-ku, Tokyo 113-0033, Japan.
}

(Received May 21, 2011; Accepted September 17, 2011; Published online September 28, 2011)

\begin{abstract}
Topical dermatological formulations of non-steroidal anti-inflammatory drugs (NSAIDs) are reported to show their pharmacological effect partially through the systemic circulation, and to induce systemic side effects. However, pharmaceutical equivalence and pharmacokinetic bioequivalence between brand-name and generic products are not required. Therefore, we aimed to predict systemic drug exposure from brand-name and nine generic ketoprofen tapes. In vitro release profiles were examined using the paddle-over-disk method, then analyzed by the W. I. Higuchi equation incorporating an initial burst effect. Pharmacokinetic parameters were estimated from observed release profiles and the reported time-plasma concentration profile of the brand-name product. Plasma concentration profiles of generic products were predicted from the observed release profiles and the pharmacokinetic parameters of the brand-name product. In vitro release profiles differed markedly, and estimated release rates for initial burst effect and at 24 hours ranged from 4.20 to $88.75 \%$ and from 45.27 to $95.83 \%$, respectively. The predicted plasma concentration profile of each product reflected its release profile, and estimated $C_{\max }$ ranged from 61.70 to $290.30 \mathrm{ng} / \mathrm{mL}$ (0.46- to 2.15 -fold $v s$. brand-name product). Generic products were classified into three types, i.e., systemic exposure comparable with, higher than and lower than that of brand-name product. $\mathrm{C}_{\max }$ was predicted to increase with enhanced skin permeability for all products, but the increase rates differed among products. These results suggest that safety and efficacy differ between brand-name and generic ketoprofen tapes. Healthcare professionals should carefully monitor systemic side effects, especially when switching from brand-name to generic products for which higher systemic exposure is predicted.
\end{abstract}

Key words_ — ketoprofen tape; generic product; systemic exposure; pharmacokinetic model; in vitro release test; adverse effect

\section{緒言}

非ステロイド性消炎鎮痛剂（Non-Steroidal AntiInflammatory Drugs; NSAIDs) は, 経口剂, 坐剂, 注射剂などといつた全身作用を目的とした製剤のみ ならず，テープ剂，パップ剂，軟膏剂，ゲル剂，ク リーム剤，ローション剂などといつた局所皮膚適用 製剂としても広く利用されている．NSAIDs の局所 皮膚適用製剂は局所作用を目的としているにもかか わらず，その使用による様々な全身性の副作用が報 告されている。例えば，ケトプロフェン外用剤の場 合，全身への移行により発現すると考えられる副作

$a$ 東京大学大学院薬学系研究科, $b$ 同院情報学環

*e-mail: sawada@mol.f.u-tokyo.ac.jp
用として，アスピリン喘息, ${ }^{1-4)}$ 胎児動脈管収縮, ${ }^{5)}$ 急性腎不全6)が報告されている。ささらに，NSAIDs の局所皮膚適用製剂では，適用部位からの直接の経 路のみならず，全身血流からの経路も薬理作用に寄 与するとの報告もある. ${ }^{7,8)}$ そのため, NSAIDs 局所 皮膚適用製剂を適正に使用するためには，全身移行 性に関する情報が必須である。

NSAIDs の局所皮膚適用製剂には，多くの後発医 薬品が承認, 販売されている. 先発医薬品から後発 医薬品への切り替え時などにおける安全性を確保す る上で，全身移行性に関する情報が必須である。し かしながら，NSAIDs 局所皮膚適用製剂の後発医薬 品の承認申請において，ヒトでの全身移行性が先発 医薬品と同等性であることは求められておらず，こ 
れらの情報は不明である。すなわち，厚生労働省の 『局所皮膚適用製剂の後発医薬品のための生物学的 同等性試験ガイドライン』9)においては，局所皮膚 適用製剂の治療上の同等性を保証するために，作用 部位近傍である角層内の薬物濃度に主眼をおいた皮 膚薬物動態学的試験が基本的試験とされ，全身循環 中の薬物濃度をみる薬物動態学的試験は代替試験と して位置づけられているのみである。また，作用強 度の強いステロイド剤など一部の薬物は，バリア能 が低下した皮膚に適用されたときに全身循環血流に 到達する薬物量（曝露量）が先発医薬品と同程度又 は許容される程度であることを確認することが求め られているが，NSAIDs はその対象ではない，さら に，本ガイドライン制定以前に承認，販売された後 発医薬品では，ヒトでの生物学的同等性試験がかな らずしも行われていない，実際に，わが国ではケト プロフェンテープの後発医薬品として 9 製剤が承 認，販売されているが，ヒトでの薬物動態学的試験 が行われているのは 9 製剤中 1 製剂のみであり，他 の 8 製剤ではラットでの薬理学的試験をもつて同等 性が示されているに過ぎない. ${ }^{10-18}$

以上のように，NSAIDs の局所皮膚適用製剂の後 発医薬品の全身移行性に関する情報は副作用など安 全性を評価する上で必要であるが，ほとんど存在し ない，そこで本研究では，ケトプロフェンテープ製 剂を対象に，in vitro 放出試験及び薬物動態学的 （PK）モデル解析を行い, 先発医薬品及び後発医薬 品 9 製剂の全身移行性を予測し，後発医薬品を選択 する上で安全性を評価する 1 つの指標を提供するこ とを目的とした。

\section{方法}

1. 試薬及び試験製剤 ケトプロフェンテープ $20 \mathrm{mg}$ 製剂の先発医薬品（A 製剂）及び後発医薬品 9 製剂（B-J 製剂）は各販売会社より購入した (Table 1)。ケトプロフェン標準品は和光純薬株式 会社（大阪）より購入した。その他の試薬はすべて 特級品を用いた。

2. In vitro 放出試験ケトプロフェンテープ 製剤からのケトプロフェン放出試験は，パドルオー バーディスク法（米国薬局方（USP） Apparatus 5)

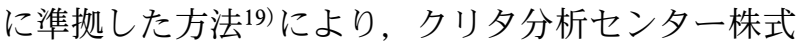
会社（茨城）に委託して行った。放出試験装置は,
Table 1. Brand-name (Product A) and Generic (Product BJ) Ketoprofen Tapes $(20 \mathrm{mg}$ ) Analyzed in This Study

\begin{tabular}{|c|c|c|c|}
\hline Product & Trade name & Company & $\begin{array}{c}\text { Lot } \\
\text { number }\end{array}$ \\
\hline A & $\begin{array}{l}\text { Mohrus Tape } 20 \\
\text { mg }\end{array}$ & $\begin{array}{l}\text { Hisamitsu Pharmaceu- } \\
\text { tical Co., Inc. }\end{array}$ & JB03T \\
\hline B & Ketotax Tape* & $\begin{array}{l}\text { Rakool Pharmaceutical } \\
\text { Marketing Co., Ltd. }\end{array}$ & K226K \\
\hline $\mathrm{C}$ & $\begin{array}{l}\text { Ketoprofen Tape } \\
20 \mathrm{mg} \text { "Rakool" }\end{array}$ & $\begin{array}{l}\text { Rakool Pharmaceutical } \\
\text { Marketing Co., Ltd. }\end{array}$ & B298K \\
\hline $\mathrm{D}$ & $\begin{array}{l}\text { Ketoprofen Tape } \\
20 \text { mg "Nichi- } \\
\text { Iko" " }\end{array}$ & $\begin{array}{l}\text { Nichi-Iko Pharmaceu- } \\
\text { tical Co., Ltd. }\end{array}$ & $9 \mathrm{~N} 14$ \\
\hline E & $\begin{array}{l}\text { Touchron Tape } \\
20\end{array}$ & $\begin{array}{l}\text { Sanwa Kagaku } \\
\text { Kenkyusho Co., Ltd. }\end{array}$ & 9T11 \\
\hline $\mathrm{F}$ & Patell Tape 20 & $\begin{array}{l}\text { Kyorin Rimedio Co., } \\
\text { Ltd. }\end{array}$ & 270910 \\
\hline G & $\begin{array}{l}\text { Frestol Tape } 20 \\
\mathrm{mg}\end{array}$ & $\begin{array}{l}\text { Towa Pharmaceutical } \\
\text { Co., Ltd. }\end{array}$ & A012 \\
\hline $\mathrm{H}$ & $\begin{array}{l}\text { Rheila Tape } 20 \\
\text { mg }\end{array}$ & $\begin{array}{l}\text { Nichi-Iko Pharmaceu- } \\
\text { tical Co., Ltd. }\end{array}$ & X920 \\
\hline I & Raynanon tape & $\begin{array}{l}\text { Nippon Chemiphar } \\
\text { Co., Ltd. }\end{array}$ & XX01 \\
\hline $\mathrm{J}$ & Romal Tape 20 & $\begin{array}{l}\text { Mochida Pharmaceuti- } \\
\text { cal Co., Ltd. }\end{array}$ & $9 \mathrm{~B} 11$ \\
\hline
\end{tabular}

* Trade name was changed to Ketoprofen Tape 20 mg "Toko" in January 2011 .

溶出試験器 NTR-6200AC（富山産業株式会社，大 阪）を用いた。各試験製剤を $3 \mathrm{~cm} \times 3 \mathrm{~cm}$ に切り， 接着剤を用いてステンレススチールディスクに固定 した。これを液温 $32 \pm 0.5^{\circ} \mathrm{C}$ の日局崩壊試験第 2 液 （pH 6.8） $900 \mathrm{~mL}$ を満たしたベッセルの底に静置 し，その後速やかに毎分 100 回転でパドルを回転さ せることで試験を開始した。試験開始 $0.5,1,2,8$ 時 間後に溶出液 $10 \mathrm{~mL}$ を採取した.

3. ケトプロフェンの定量＼cjkstart溶出液中のケトプ ロフェンの定量は HPLCにより行った。溶出液を 孔径 $0.45 \mu \mathrm{m}$ 以下のメンブレンフィルターで濾過 し，試料溶液とした。また，別にケトプロフェン標 準品 $40 \mathrm{mg}$ をアセトニトリル $100 \mathrm{~mL}$ に溶かし，こ の液 $1 \mathrm{~mL}$ に日局崩壊試験第 2 液（pH 6.8）を加え て $100 \mathrm{~mL}$ としたものを標準溶液とした．HPLC 装 置は, HPLC アライアンス 2695 （検出器：フォト ダイオードアレイ検出器, 日本ウォーターズ株式会 社，東京）を用いた。 カラムは，内径 $4.6 \mathrm{~mm}$, 長 さ $15 \mathrm{~cm}$ のステンレス管に $5 \mu \mathrm{m}$ の液体クロマトグ ラフィー用オクタデシルシリル化シリカゲルを充填 したものを用いた．移動相はリン酸緩衝溶液（pH 3.5）:アセトニトリル：水 $=2: 43: 55$, 流速は 1.2 
$\mathrm{mL} / \mathrm{min}$ ，検出波長は $257 \mathrm{~nm}$ とした。試料溶液及 び標準溶液 $25 \mu \mathrm{L}$ をインジェクトし，定量分析には ピーク面積測定法を用いた。

4. In vitro 放出プロファイルの解析 テープ 剤の in vitro での放出においては，試験開始時に瞬 時に一定量が放出される初期 burst 現象が起こるこ とがある.In vitro 放出試験における各ケトプロフ エンテープ製剤からのケトプロフェンの放出は，試 験開始初期に burst 現象による放出が起こり，その 後の放出は W. I. Higuchi 式20)に従うと仮定した. W. I. Higuchi 式の $\sum$ 項を $n=1-10$ で近似すると, 試験開始後の時間 $\mathrm{t}$ におけるケトプロフェンの放出 率 X（\%）は Eqs.（1），(2)で表される.

$$
\begin{aligned}
X= & \alpha+(100-\alpha)\left[1-\frac{8}{\pi^{2}}\left(\sum_{n=1}^{10} \frac{1}{(2 n-1)^{2}}\right.\right. \\
& \left.\left.\times \exp \left(-(2 n-1)^{2} \beta t\right)\right)\right] \\
\beta= & \frac{\pi^{2} D}{4 L^{2}}
\end{aligned}
$$

ここで， $\alpha$ は試験開始初期の burst 現象による放 出率 (\%), $\beta$ は初期 burst 後の W. I. Higuchi 式に おける放出速度定数 $(/ \mathrm{h}), \mathrm{D}$ は製剤内でのケトプ ロフェンの拡散定数 $\left(\mathrm{m}^{2} / \mathrm{h}\right), \mathrm{L}$ は製剤の厚さ $(\mathrm{m})$ である。

非線形最小二乗法 (MLAB, Civilized Software Inc., Bethesda, MD) により，Eq. (1)を各ケトプロ フェンテープ後発医薬品（B-J 製剂）の in vitro 放 出試験の実測值にそれぞれ当てはめ，製剤毎にパラ メータ $\alpha, \beta$ を算出した.

\section{In vitro 放出プロファイルを考慮した $\mathrm{PK}$ モ} デル ケトプロフェンテープ製剤を皮膚に貼付後 のケトプロフェンの体内動態を表現するモデルとし て，テープ，皮膚表面及び血液の 3 つのコンパート メントからなる PK モデル（Fig. 1）を以下の仮定 に基づき構築した。

1）皮膚貼付後の in vivo 放出プロファイルは, in vitro 放出プロファイルと等しい.

2） テープ貼付後のケトプロフェンの放出にはラ グタイム tlag（h）が存在し，初期 burst によ り放出するケトプロフェン $(\alpha)$ は，ラグタイ 厶後瞬時にテープから皮膚表面へ放出される.

3） ケトプロフェンの皮膚中の透過及び血液から の消失は，それぞれ一次速度定数 $\mathrm{ka}(/ \mathrm{h})$ 及

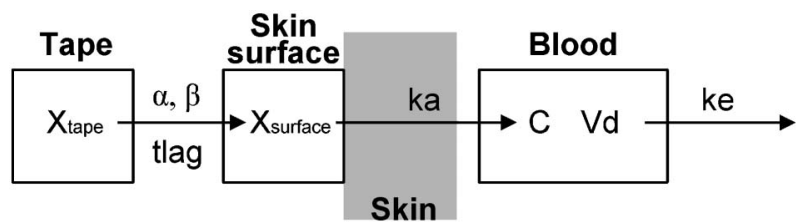

Fig. 1. Pharmacokinetic Model Incorporating In Vitro Release Profiles for Ketoprofen Tape

$\mathrm{X}_{\text {tape }}$ : drug amount in tape compartment $(\mu \mathrm{g}), \mathrm{X}_{\text {surface: }}$ drug amount in skin surface $(\mu \mathrm{g}), \mathrm{C}$ : drug concentration in blood compartment $(\mathrm{ng} / \mathrm{mL}), \alpha$ : release rate for initial burst effect (\%), $\beta$ : release rate constant from tape compartment $(/ \mathrm{h})$, ka: permeation rate constant through skin $(/ \mathrm{h})$, ke: elimination rate constant from blood compartment $(/ \mathrm{h}), \mathrm{Vd}$ : distribution volume of blood compartment (L), tlag: lag time for release initiation (h).

び ke（/h）に従う.

4）製剂の特性の影響を受けず，薬物自体の特性 及び生体側の要因に基づくと考えられる ka， $\mathrm{ke}$, tlag 及びケトプロフェンの分布容積 $\mathrm{Vd}(\mathrm{L})$ は製剤間で等しい.

構築した PK モデルにおけるマスバランス式 [Eqs. (3)-(5)] を以下に示す.

$$
\begin{aligned}
& \frac{d X_{\text {tape }}}{d t} \\
& =\left\{\begin{array}{cc}
0 & (t<\text { tlag }, t>24) \\
- & \text { Dose } \cdot\left(1-\frac{\alpha}{100}\right) \cdot \frac{8 \cdot \beta}{\pi^{2}}\left[\sum _ { n = 1 } ^ { 1 0 } \operatorname { e x p } \left\{-(2 n-1)^{2}\right.\right. \\
& \times \beta \cdot(t-\text { tlag })\}] \quad(\text { tlag } \leq t \leq 24)
\end{array}\right.
\end{aligned}
$$

$\frac{d X_{\text {surface }}}{d t}$

$$
=\left\{\begin{array}{l}
0 \quad(t<\text { tlag }) \\
-\frac{d X_{\text {tape }}}{d t}-k a \cdot X_{\text {surface }} \quad(t \geq \text { tlag })
\end{array}\right.
$$

$\frac{d C}{d t}=\frac{k a \cdot X_{\text {surface }}}{V d}-k e \cdot C$

ここで，Dose は貼付したテープ製剂中の薬物投 与量 $(\mu \mathrm{g}), \mathrm{X}_{\text {tape }}$ はテープコンパートメント中の薬 物量 $(\mu \mathrm{g}), \mathrm{X}_{\text {surface }}$ は皮膚表面の薬物量 $(\mu \mathrm{g}), \mathrm{C}$ は 血液コンパートメント中の薬物濃度 $(\mathrm{ng} / \mathrm{mL})$ で ある.

ケトプロフェンテープ先発医薬品（A 製剤）の in vitro 放出試験により得られた放出率の実測值, 先発医薬品 $20 \mathrm{mg}$ 製剂を健康成人に 24 時間単回貼 付後の製剤の残存量から算出される吸収率の報告 值, ${ }^{21)}$ 及び，先発医薬品 $20 \mathrm{mg}$ 製剂を健康成人に 
24 時間単回貼付時のケトプロフェンの血漿中濃度 推移の報告值 ${ }^{21)}$ に対して, Eq. (1) 及び Eqs. (3)(5)を非線形最小二乗法（MLAB）により同時に当 てはめ, パラメータ $(\alpha, \beta, \mathrm{ka}, \mathrm{ke}, \mathrm{Vd}, \mathrm{tlag})$ を算出 した.

6. 血漿中濃度推移の予測 ケトプロフェン テープ後発医薬品 9 製剂（B-J 製剤）について，前 述の仮定 4）に従い，テープからの放出過程以降の パラメータ（ka, ke, Vd, tlag）は先発医薬品（A 製 剂）の解析により得られた值に固定し，各製剤の in vitro 放出プロファイルの解析によって得られた パラメータ $\alpha, \beta$ を用いて， $20 \mathrm{mg}$ 製剂を 24 時間単 回貼付した時のケトプロフェン血漿中濃度推移をシ ミュレートした.

また, 先発医薬品（A 製剂）及び後発医薬品（B -J 製剤）について，ka 值が $2 ， 3 ， 5 ， 10$ 倍になつた 際のケトプロフェン血漿中濃度推移をシミュレート した。得られた血漿中濃度推移から最高血漿中濃度 $\mathrm{C}_{\max }, 0-24$ 時間の血中濃度下面積 $\mathrm{AUC}_{0-24}$ を算出し た.

結果

1. In vitro 放出試験 ケトプロフェンテープ
先発医薬品 $(\mathrm{A}$ 製剂) 及び後発医薬品 9 製剂 $(\mathrm{B}-\mathrm{J}$ 製剂）について，in vitro 放出試験を行つた結果を Fig. 2 に示す. In vitro 放出プロファイルは製剤間 で大きく異なった．また，すべての製剂において， 試験開始初期に burst 現象による放出が認められ た。なお，目視で確認した限り，膏体の崩壊液への 懸濁，膏体の基布からの剥離，膏体と基布の間への 崩壊液の浸潤等は起こらなかった。

\section{2. 先発医薬品の PK モデル解析 In vitro 放} 出プロファイルを考慮したケトプロフェンテープ製 剂貼付時の PK モデルを構築した（Fig. 1)。構築し たモデルにより，ケトプロフェンテープ先発医薬品 （A 製剂）の in vitro 放出プロファイル，先発医薬 品 $20 \mathrm{mg}$ 製剂 24 時間単回貼付時の吸収率及びその ときの血漿中濃度推移は良好に表現された [Figs. 2 (A) and 3]. 得られたケトプロフェンの PK パラ メー夕を Table 2 に, 先発医薬品の放出パラメー夕 $\alpha, \beta$ を Table 3 に示す.

\section{3. 後発医薬品の in vitro 放出プロファイルの解} 析 ケトプロフェンテープ後発医薬品 (B-J 製剂) の in vitro 放出プロファイルは，Eq.（1）により良 好に表現された（Fig. 2)。得られた後発医薬品の 放出パラメー夕 $\alpha, \beta$ を Table 3 に示す。初期 burst
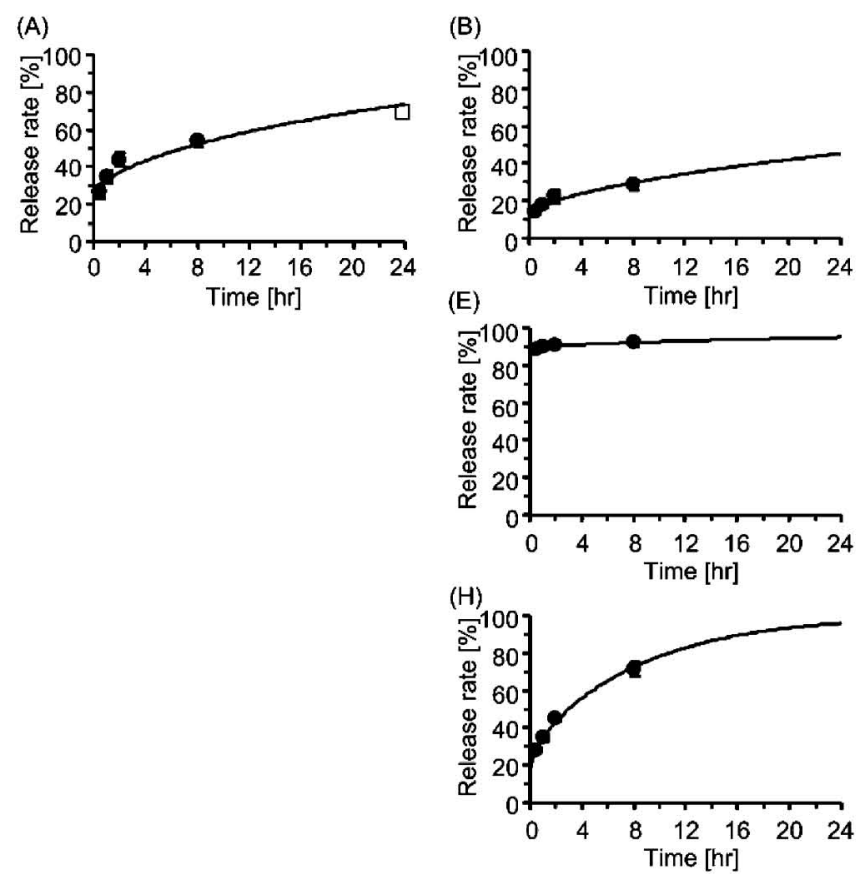

(C)
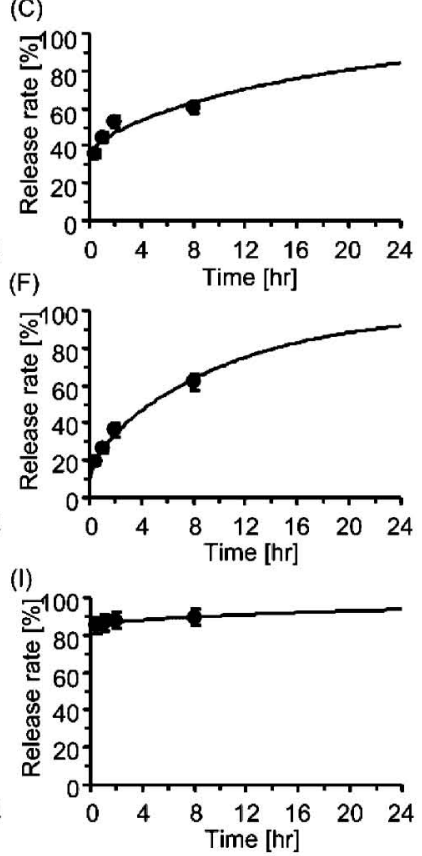

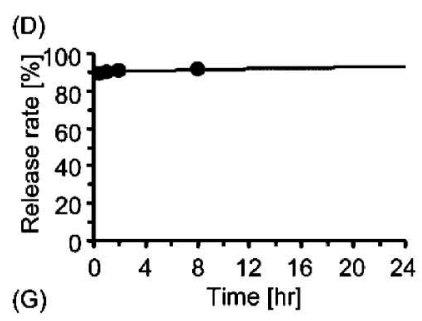

(G)
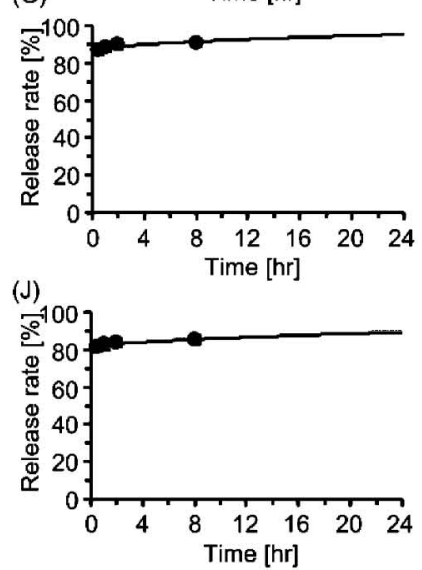

Fig. 2. In Vitro Release Profiles of Brand-name (Product A) and Generic (Product B-J) Ketoprofen Tapes

(A) : brand-name ketoprofen tape (Product A). (B) - (J) : generic ketoprofen tapes (Product B-J), respectively. Closed circles represent in vitro release rate $(n$ $=3$, mean \pm S.D. $)$. Open square represents absorption rate on topical application to healthy subjects for 24 hours $\left(n=6\right.$, mean). ${ }^{21)}$ The lines were calculated by as described in the method. 


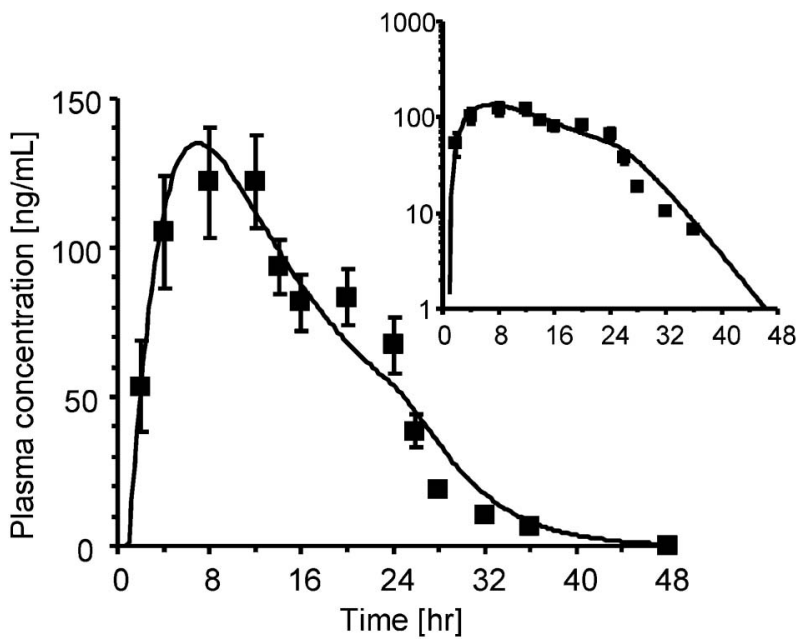

Fig. 3. Pharmacokinetic Analysis of the Plasma Concentration-time Profile of Brand-name Ketoprofen Tape (Product A)

Brand-name ketoprofen tape (Product A, $20 \mathrm{mg}$ ) was administered to six healthy subjects at single dose for 24 hours. ${ }^{21)}$ Symbols represent the observed mean values \pm S.D. The line was calculated by fitting the plasma concentration-time profile and the in vitro release profile [Fig. 2(A)] to the pharmacokinetic model simultaneously as described in the text. Inset: Loglinear plot.

Table 2. Pharmacokinetic Parameters of Ketoprofen Tapes

\begin{tabular}{ccc}
\hline \hline Parameter & Unit & Estimate \pm S.D. \\
\hline $\mathrm{ka}$ & $/ \mathrm{h}$ & $0.215 \pm 0.156$ \\
$\mathrm{ke}$ & $/ \mathrm{h}$ & $0.338 \pm 0.447$ \\
$\mathrm{Vd}$ & $\mathrm{L}$ & $17.9 \pm 21.1$ \\
tlag & $\mathrm{h}$ & $0.973 \pm 0.679$ \\
\hline
\end{tabular}

ka: permeation rate constant through skin, ke: elimination rate constant from blood compartment, $\mathrm{Vd}$ : distribution volume of blood compartment, tlag: lag time for release initiation.

現象による放出率 $\alpha$ は 4.20-88.75\%，初期 burst 後 の放出速度定数 $\beta$ は $0.012-0.118 / \mathrm{h}$ と製剤間で大き く異なつた。また， 24 時間後の放出率も，45.27$95.83 \%$ と製剤間で大きく異なつた.

\section{4. 健常時及び皮膚透過性亢進時の血漿中濃度推} 移の予測＼cjkstart得られたパラメータを用いて，各製剂 貼付時の血中濃度推移を予測するとともに, ka $(0.21 / \mathrm{h}$; 健康成人への貼付時のデータ $)$ が $2,3,5$, 10 倍になった場合（皮膚の透過性が充進した状態） の血漿中濃度推移を予測した（Fig. 4)。予測した 血中濃度推移から算出した $\mathrm{C}_{\max }(\mathrm{ng} / \mathrm{mL}), \mathrm{AUC}_{0-24}$ $(\mathrm{ng} \cdot \mathrm{h} / \mathrm{mL})$ を Fig. 5 に示す。

健常時（ka 1 倍）の各製剤の血漿中濃度推移は, in vitro 放出プロファイルを反映した結果となり,
Table 3. Relationship between In Vitro Release Profiles and Estimated Plasma Concentration Profiles of Ketoprofen Tapes

\begin{tabular}{|c|c|c|c|c|}
\hline \multirow{2}{*}{ Product } & \multirow{2}{*}{$\alpha[\%]$} & \multirow{2}{*}{$\beta[/ \mathrm{h}]$} & $\mathrm{C}_{\max }{ }^{a)}$ & \multirow{2}{*}{$\frac{\mathrm{C}_{\max }(\mathrm{ka} \times 10)^{b)}}{\mathrm{C}_{\max }(\mathrm{ka} \times 1)}$} \\
\hline & & & $\mathrm{C}_{\max }(\mathrm{A})$ & \\
\hline \multicolumn{5}{|c|}{ Type medium_1 } \\
\hline A & 21.0 & 0.0514 & 1.00 & 1.78 \\
\hline $\mathrm{C}$ & 30.5 & 0.0530 & 1.15 & 1.96 \\
\hline \multicolumn{5}{|c|}{ Type medium_2 } \\
\hline $\mathrm{F}$ & 4.20 & 0.0945 & 1.11 & 1.42 \\
\hline $\mathrm{H}$ & 12.7 & 0.118 & 1.28 & 1.53 \\
\hline \multicolumn{5}{|c|}{ Type low } \\
\hline B & 7.48 & 0.0135 & 0.457 & 1.66 \\
\hline \multicolumn{5}{|c|}{ Type high } \\
\hline $\mathrm{D}$ & 88.8 & 0.0125 & 2.15 & 2.44 \\
\hline $\mathrm{E}$ & 88.2 & 0.0269 & 2.15 & 2.43 \\
\hline G & 86.0 & 0.0362 & 2.12 & 2.42 \\
\hline I & 83.9 & 0.0301 & 2.07 & 2.42 \\
\hline $\mathrm{J}$ & 80.1 & 0.0170 & 1.97 & 2.42 \\
\hline
\end{tabular}

$\alpha$ : release rate for initial burst effect, $\beta$ : release rate constant from tape compartment. a) Ratio of estimated $C_{\max }$ of each product to that of product $\mathrm{A}$ (brand-name product). b) Ratio of estimated $\mathrm{C}_{\max }$ for normal ka to that in the case of increased skin permeability (10 times larger than ka).

$\mathrm{C}_{\max }$ は 61.70-290.30 ng/mL（先発医薬品比 0.462.15）と製剤間で大きく異なった。一方， $\mathrm{AUC}_{0-24}$ も $1073-3026 \mathrm{ng} \cdot \mathrm{h} / \mathrm{mL}$ （先発医薬品比 $0.50-1.40$ ) と製剤間で異なったが， $\mathrm{C}_{\max }$ よりも製剤間の差は 小さかった.

また，各製剂の $\mathrm{C}_{\text {max }}$ は皮膚透過性の充進（ka 2, $3 ， 5 ， 10$ 倍）に伴い上昇し，先発医薬品（A 製剂） の健常時（ka1 倍）と比較して, 最大 5.24 倍（製 剂 $\mathrm{E}, \mathrm{ka} 10$ 倍）の差が予測された。一方， $\mathrm{AUC}_{0-24}$ は，いずれの製剂においても皮膚透過性の充進に伴 う変化はほとんどなかった。

5. 製剤のタイプ分け In vitro 放出プロファ イル及び予測された全身移行性を基に，各製剤を夕 イプ分けした結果，以下の 4 タイプに分かれた (Table 3).

1）Type Medium_1：先発医薬品と比較して, 全身移行性が同等であり，また初期 burst 現象 による放出率 $\alpha$, 初期 burst 後の放出速度定数 $\beta$ も同等である (A, C 製剤).

2) Type Medium_2: 先発医薬品と比較して, 全身移行性は同等であるが， $\alpha$ が小さく, $\beta$ が 大きい $(\mathrm{F}, \mathrm{H}$ 製剤). 

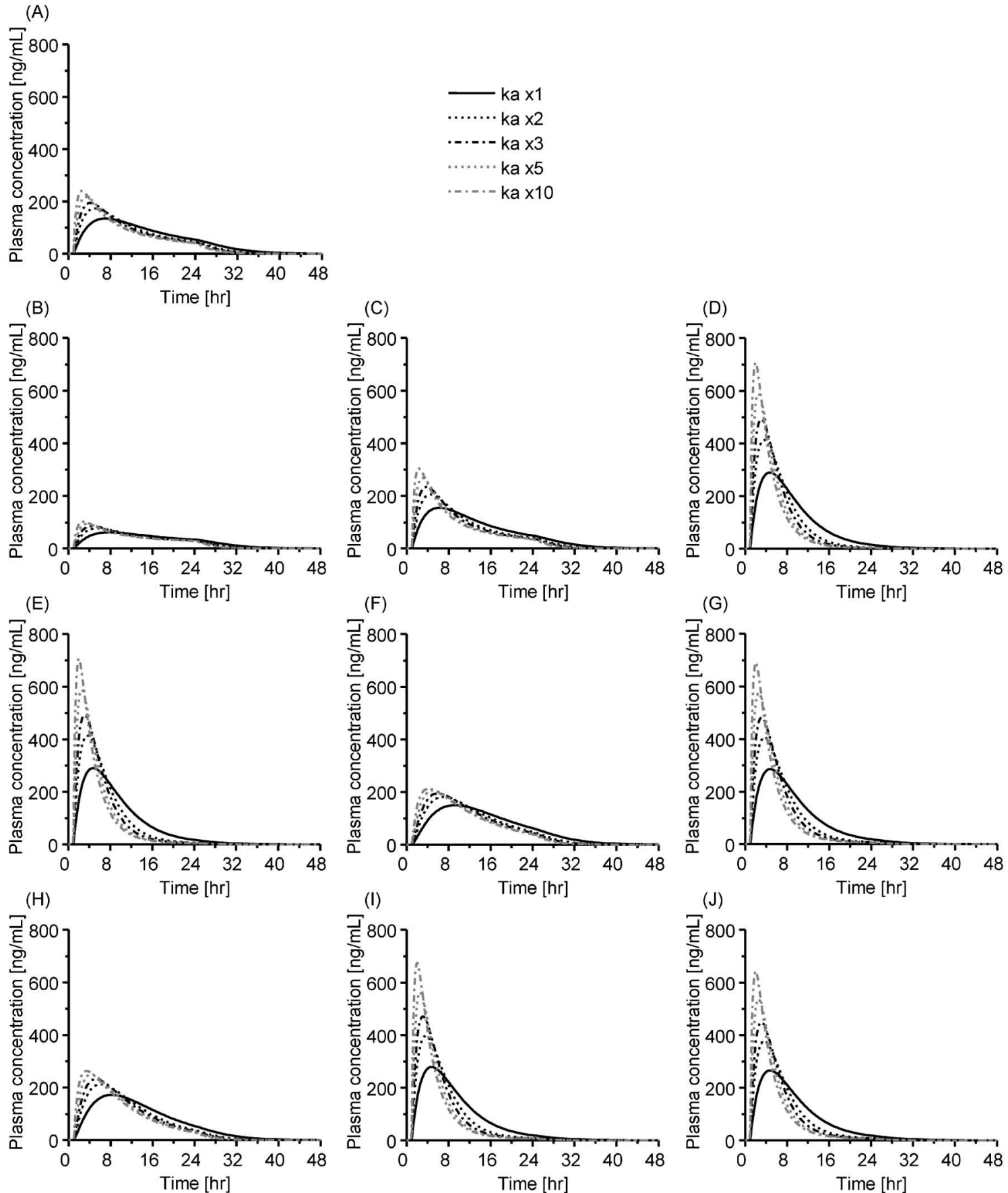

Fig. 4. Predicted Concentration-time Profiles

Brand-name (Product A) and generic (Products B-J) ketoprofen tapes in the normal skin $(\mathrm{ka} \times 1)$ and skin with increased permeability $(\mathrm{ka} \times 2, \times 3, \times 5, \times$ 10).

3） Type Low：先発医薬品と比較して，全身移 行性が低く，また $\alpha, \beta$ がともに小さい（B 製 剂)

4） Type High：先発医薬品と比較して，全身移 行性が高く，また $\alpha$ が非常に大きく， $\beta$ が小さ い (D, E, G, I, J 製剂)。

考察

本研究から, ケトプロフェンテープの in vitro 放 出プロファイル及び予測された全身移行性は, 先発 医薬品及び後発医薬品間で大きく異なることが明ら かになった（Figs. 2 and 4, Table 3)。 NSAIDs の 投与量に対する AUC の值（AUC/Dose）を外用剤 


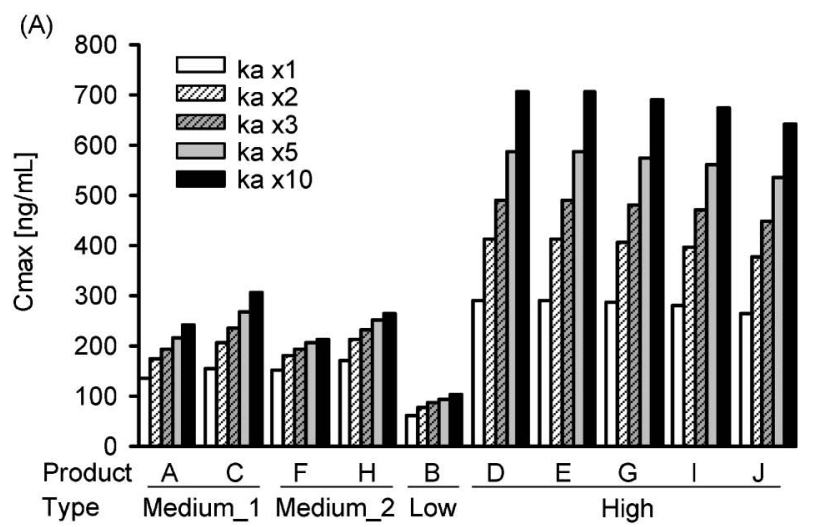

(B)

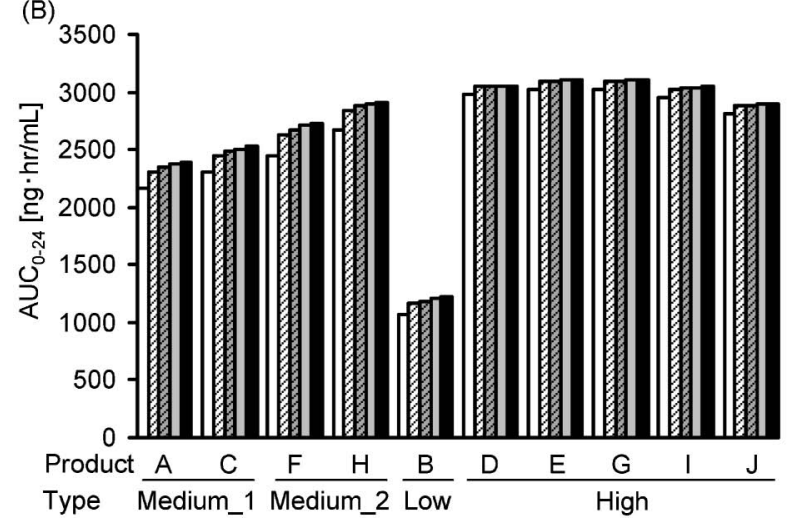

Fig. 5. Predicted (A) $\mathrm{C}_{\max }$ and (B) $\mathrm{AUC}_{0-24}$ of Ketoprofen Tapes in Various Skin Permeability Conditions

Type Medium_1: The extent of systemic exposure, $\alpha$ (release rate for initial burst effect) and $\beta$ (release rate constant from tape) values are comparable with those of the brand-name ketoprofen tape. Type Medium_2: The extent of systemic exposure is comparable with that of the brand-name ketoprofen tape, and the $\alpha$ value is lower and the $\beta$ value is higher than those of the brand-name ketoprofen tape. Type Low: The extent of systemic exposure is lower than that of the brand-name ketoprofen tape, and the $\alpha$ and $\beta$ values are lower than those of the brand-name ketoprofen tape. Type High: The extent of systemic exposure is higher than that of the brand-name ketoprofen tape, and the $\alpha$ value is higher and the $\beta$ value is lower than those of the brand-name ketoprofen tape.

と全身作用目的製剤とで比較すると，ロキソプロフ エンパップ及び錠剤でそれぞれ 5.2422) 及び 112, ${ }^{23)}$ ジクロフェナクテープ及び錠剤でそれぞれ 7.9324 及び $39.9,{ }^{25)}$ ケトプロフェンパップ及び SR カプセ ルでそれぞれ 10.726) 及び 16027) であり，外用剤で 小さい值をとる.しかし，ケトプロフェンテープは 12221) と SR カプセル (160) 27)に匹敵するほど高く， わずか数枚の適用により，全身作用目的製剂と同等 の全身曝露となると考えられる．Type Low の製剂 は全身移行性が低いと予測されたが，ケトプロフェ ンテープでは全身血流からの経路も薬理作用に寄与 していると考えられることから, ${ }^{8)}$ 先発医薬品と比 較して治療効果が劣る可能性がある。実際，B 製剂 において先発医薬品と比較して効果が劣ると訴えた
患者がいたことが報告されている. ${ }^{28)}$ 一方，Type High の製剤は全身移行性が高いと予測されたこと から，先発医薬品と比較して全身性の副作用の発現 頻度の上昇が懸念される。ケトプロフェン外用剂で 報告されている副作用症例の中で，アスピリン喘息 は, $0.3 \%$ 湿布剤から $2 \%$ テープ剤への切り替え時 に発現したこと，また，発作の発現時間が血中濃度 推移と関係していると考えられたことから， dose dependent であると推測されている. 1,4) また，胎児 動脈管収縮は，プロスタグランジンの合成阻害によ つて起こること, ${ }^{29)}$ ラットにおいて動脈管収縮度が dose dependent であること ${ }^{30,31)}$ が報告されている.

これらのことから，アスピリン喘息や胎児動脈管収 縮は，血中濃度依存的であり，先発医薬品から Type High 製剂への切り替え時においてこれらの副 作用が発現することが懸念される.

ケトプロフェンテープは局所皮膚適用製剤である ことから, 皮膚中の薬物濃度推移を予測することも 有益であると考えられた。しかし，ヒトにケトプロ フェンテープ剂を適用した際の皮膚中薬物量 (濃度) について，解析に耐え得る報告デー夕はなく，皮膚 中薬物量（濃度）の時間推移を精度高く予測するこ とは不可能であった。 そのため, 本モデルでは角層 の透過及び真皮の透過をまとめて 1 つのパラメータ kaによって表現し，ka を大きくすることによって 皮膚透過性が亢進した状態を表現した.

Type Medium である製剤 $\mathrm{H}$ においては，健康成 人を対象とした臨床試験において，20 mg 製剂を 24 時間単回貼付時のケトプロフェン血漿中濃度推 移が報告されている. ${ }^{16)}$ 本研究の in vitro 放出試験 結果及び PK モデルを用いて，20 mg 製剂 24 時間 単回貼付時の血中濃度推移を予測したところ, 臨床 試験の結果は良好に表現され（Fig. 6)，少なくと も Type Medium の製剤に関しては本解析の妥当性 が示された.

本モデル解析においては, 皮膚貼付後の in vivo 放出プロファイルは，製剂毎の in vitro 放出試験の 放出プロファイルと等しいと仮定した. In vitroに おいてはシンク条件が成り立つと考えられるが，ヒ 卜（in vivo） では主に角質層がバリアあるいはリ ザーバーの役割を果たし, ${ }^{32}$ 製剤からの薬物の放出 を制御する可能性がある。また，ニトログリセリン 放出制御製剂及び軟膏適用時の血漿中濃度推移の解 


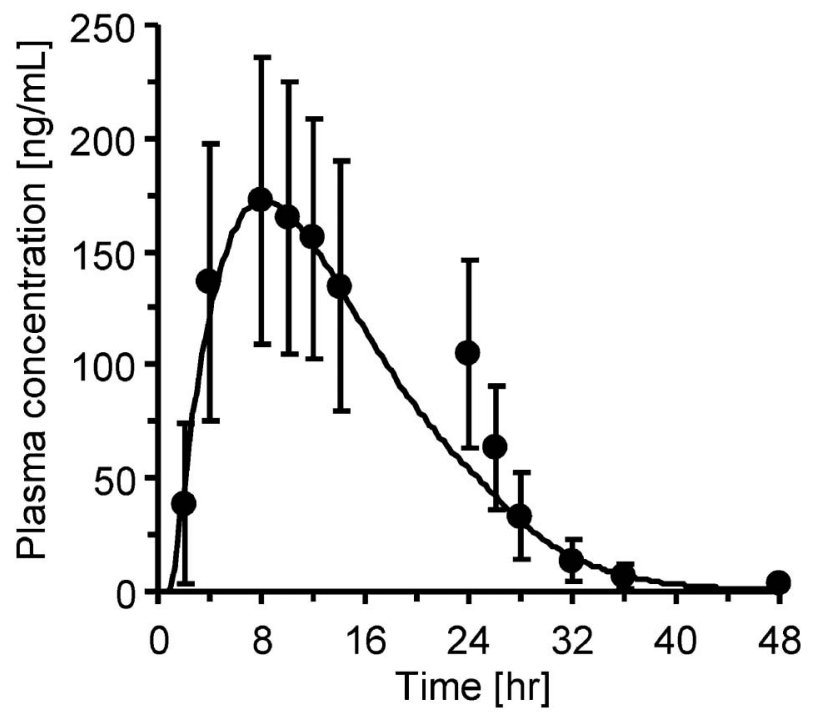

Fig. 6. Comparison of Simulated and Observed Plasma Concentration Profile of Generic Ketoprofen Tape (Product H)

Generic ketoprofen tape (Product H, 20 mg) was administered to 20 healthy subjects at single dose for 24 hours. ${ }^{16)}$ Symbols represent the observed mean values \pm S.D. The line represents the simulated profile based on the pharmacokinetic model described in the text.

析に当たって，角質層から製剤への薬物の戻りを考 慮した PK モデルも提唱されている. ${ }^{33)}$ そこで，皮 膚から製剂への移行を考慮したモデルを用いて，先 発医薬品 $20 \mathrm{mg}$ 製剂を健康成人に 24 時間単回貼付 時のケトプロフェンの血漿中濃度推移のデー夕21)を 解析したところ，予測結果は今回構築したモデル (Fig. 1) とほぼ同等であった (data not shown). このことから，角質層から製剤への薬物の戻りを考 慮しなくても，良好な予測が可能であると推測され る.

一方で，ニトログリセリン皮膚適用製剂につい て，皮膚を介さないレセプター溶液への放出（シン ク条件）及び皮膚を介したレセプター溶液への放出 を比較したところ，皮膚を介した場合には皮膚を介 さない場合より放出量が減少したこと，皮膚を介さ ない場合に放出量が多い製剂ほど，皮膚を介するこ とによる放出量の減少率が高かったことが報告され ている. ${ }^{34)}$ ケトプロフェンテープの場合にどの程度 皮膚による影響を受けるかは不明であるが，in vivo の放出プロファイルと in vitro 放出プロファイ ルは異なる可能性が考えられ，特に Type High の 製剤では，皮膚による制御を受け易いと推測され る.すなわち，本解析において Type High の製剤 の全身移行性を実際よりも過大評価している可能性
がある、Type Low 及び Type High の製剤に関して は，血中濃度を測定した臨床試験の報告がなく，今 後の検討課題である.

ケトプロフェンテープ先発医薬品及び後発医薬品 の in vitro 放出プロファイルは製剤間で大きく異な つた（Fig. 2)。この差異の明確な理由は不明であ るが，一般的に基剂が薬物の製剤からの放出や皮膚 透過に影響を与え得ることから, ${ }^{35)}$ 各製剤の添加物 の違いが原因の 1 つであると推測される。実際, Type High の 5 製剂（D， E, G, I, J 製剂）では添加 物がほぼ同一であり，天然ゴムラテックス，ポリブ デン，流動パラフィン，l-メントール，ジブチルヒ ドロキシトルエン, オレイン酸ソルビタン, ポリソ ルベート 80 , メタクリル酸・アクリル酸 $n$-ブチル 共重合体，クロタミトンが同一であった。また，

Type Medium 製剂（A, C, F, H 製剂）と Type Low 製剂（B 製剤）の添加物も類似しており，特に流動 パラフィン, l-メントールはすべての製剤に添加さ れていた. 10-18,21) しかし，これらの添加物が薬物の 放出に及ぼす具体的な影響については不明である。

本研究におけるモデル解析により, 皮膚透過性の 六進に伴いケトプロフェンテープの全身移行性は上 昇すると予測された（Fig. 4)。薬物の皮膚透過性 は，皮膚のバリア機能に左右される，皮膚のバリア 機能は，脂質や水分含量，角質層の厚さ，角質層内 の細胞間脂質量によって変化し，アトピー性皮膚炎 患者では，単位角質層あたりのセラミド量が減少す ることが報告されている。尔）また，アトピー性皮膚 炎患者において，皮膚のバリア能の指標である経皮 水分蒸散量（Transepidermal water loss; TEWL）が 増加し, TEWL と薬物や化合物の皮膚透過性との 間に正の相関性が認められることが報告されてい る. ${ }^{37,38)}$ また，ケトプロフェンと物理化学的性質が 近いと考えられるアセチルサリチル酸や安息香酸な ぞの有機イオン化合物の皮膚透過性を健康成人にお いて検討した結果，TEWL と透過性は正の相関関 係を示し，投与部位によって透過性が 2 倍以上異な

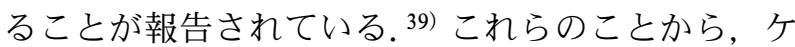
トプロフェンテープにおいても, 病変の有無や投与 部位によって数倍以上の皮膚透過性の変化があると 推測される。

皮膚透過性の六進による全身移行性 $\left(\mathrm{C}_{\max }\right)$ の上 昇率はタイプ毎に異なった（Fig. 5 and Table 3). 
(A)

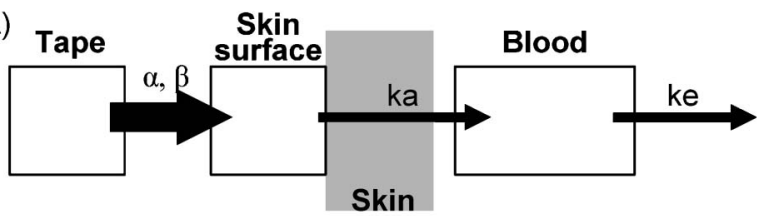

(B)

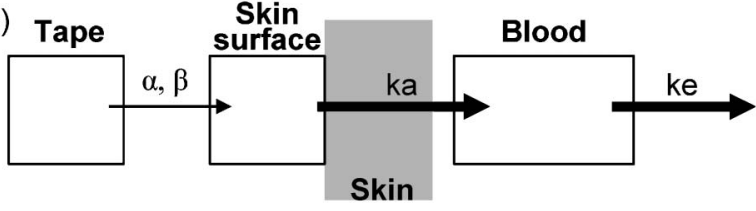

Fig. 7. Schematic Illustration of Relationship between In Vitro Release Parameters and Estimated In Vivo Pharmacokinetic Parameters of Different Type Ketoprofen Tapes (A) Type high (product D, E, G, I, J): Since the $\alpha$ value is very large, the skin permeability (i.e., ka) alternation markedly affects the time-concentration profile. (B) Type medium (product $\mathrm{A}, \mathrm{C}, \mathrm{F}, \mathrm{H}$ ) and type low (product $\mathrm{B}$ ): Since the $\alpha$ value is small and the $\beta$ value is smaller than the ka value, the skin permeability (i.e., ka) alternation hardly affects the time-concentration profile. $\alpha$ : release rate for initial burst effect, $\beta$ : release rate constant from tape, ka: permeation rate constant through skin, ke: elimination rate constant from blood compartment.

Type High の製剂は，初期 burst 現象による放出率 $\alpha$ が非常に大きいため，皮膚透過性が充進する（ka が大きくなる）と，その影響を大きく受け，全身移 行性が大きく上昇すると予測された [Table 3 and Fig. $7(\mathrm{~A})$ ]。 Type Medium 及び Type Low の製剤 は，初期 burst 現象による放出率 $\alpha$ が小さいため, 初期 burst 後の放出速度定数 $\beta$ の大きい製剤ほど全 身移行性が高いと予測された（Table 3）。さらに， $\beta<\mathrm{ka}$ であるため，皮膚透過性が充進した場合は， その影響を Type High よりも受けず，全身移行性 の上昇も小さいと予測された [Table 3 and Fig. 7 (B) ]。また，全製剤において， $\beta<\mathrm{ka}$ であること から，初期 burst の影響がなくなる終末相では，全 製剤において $\beta$ 律速であると考えられる.

本研究において, ケトプロフェンテープ先発医薬 品及び後発医薬品の in vitro 放出プロファイルは大 きく異なり，またそれから予測される全身移行性も 大きく異なった，さらに，皮膚透過性亢進による全 身移行性の上昇率も製剂毎に異なることが推測され た。ただし，これはあくまで予測結果であり，今後 はヒトでの臨床試験や副作用症例の収集が必要であ ると考えられる，現在，『局所皮膚適用製剂の後発 医薬品のための生物学的同等性試験ガイドライン』 で示されている残存量試験などでは，ある特定の時 間 1 点で評価することになっている．しかし，本研 究において，初期 burst 現象による放出率が製剤間
で大きく異なった（Fig. 2) ことや，予測された $\mathrm{C}_{\max }$ は製剤間で大きく異なる [先発医薬品比 $0.46-$ 2.15; Fig. 5(A)] が， $\mathrm{AUC}_{0-24}$ はそれほど異ならな かった [先発医薬品比 0.50-1.40; Fig. 5(B) ] こと から，ある特定の時間 1 点での評価では，正確な全 身移行性の評価が行えない可能性が考えられる，局 所皮膚適用製剂であっても，全身移行による副作用 が懸念される製剤においては，安全性を評価する資 料の 1 つとして，ヒトを対象とした薬物動態学的試 験を実施することが望まれる。

謝辞 本研究における in vitro 放出プロファイ ルの解析にあたり，貴重なご助言を賜りました城西 大学薬学部杉林堅次教授, 並びに藤堂浩明助教に謹 んで深謝いたします。

\section{REFERENCES}

1) Miyairi A., Ohori K., Yamauchi T., Respiration Research, 9, 110-112 (1990).

2) Tanaka H., Nakahara K., Sakai S., Goto K., Jpn. J. Thorac. Dis., 30, 653-657 (1992) .

3) Negishi M., Allergology, 12, 403-404 (2001).

4) Namihira T., Sakata K., Orthoped. Traumatol., 52, 302-304 (2003).

5) Kanagawa T., Tomimatsu T., Kinugasa Y., Mimura K., Ogita K., Arahori H., Kogaki S., Wada K., Kimura T., J. Jpn. Soc. Perin. Neon. Med., 44, 549 (2008).

6) Krummel T., Dimitrov Y., Moulin B., Hannedouche T., BMJ, 320, 93 (2000).

7) Singh P., Roberts M. S., J. Pharmacol. Exp. Ther., 268, 144-151 (1994).

8) Sugawara S., Ohno H., Ueda R., Ishigami M., Kubodera D., Fujiwara H., Satoh H., Yamazaki K., Jpn. Pharmacol. Ther., 14, 66316637 (1986).

9) Ministry of Health, Labour and Welfare, "Guidelines for Bioequivalence Studies of Generic Products for Topical Dermatological Use," Notification No. 1124004 of the Evaluation and Licensing Division, Pharmaceutical and Food Safety Bureau dated November 24, 2006.

10) Ketotax Tape Interview form, 5th ed., Rakool Pharmaceutical Marketing Co., Ltd., 2008.

11) Ketoprofen Tape "Rakool" Interview form, 
1st ed., Rakool Pharmaceutical Marketing Co., Ltd., 2008.

12) Ketoprofen Tape "Nichi-Iko" Interview form, 3rd ed., Nichi-Iko Pharmaceutical Co., Ltd., 2009.

13) Touchron Tape Interview form, 1st ed., Sanwa Kagaku Kenkyusho Co., Ltd., 2008.

14) Patell Tape Interview form, 12th ed., Kyorin Rimedio Co., Ltd., 2010.

15) Frestol Tape Interview form, 12th ed., Towa Pharmaceutical Co., Ltd., 2010.

16) Rheila tape $20 \mathrm{mg}$ Interview form, 8th ed., Nichi-Iko Pharmaceutical Co., Ltd., 2010.

17) Raynanon tape Interview form, 4th ed., Nippon Chemiphar Co., Ltd., 2010.

18) Romal Tape Interview form, 6th ed., Mochida Pharmaceutical Co., Ltd., 2010.

19) “The United States Pharmacopeia," 34th ed., The United States Pharmacopeial Convention, Rockville, 2011, pp. 285-286.

20) Higuchi W. I., J. Pharm. Sci., 51, 802-804 (1962).

21) Mohrus Tape Interview form, 11th ed., Hisamitsu Pharmaceutical Co., Inc., 2010.

22) “Review Report of Loxonin Pap 100 mg,", Pharmaceuticals and Medical Devices Agency, 2005.

23) Loxonin Tablets Interview form, 5th ed., Daiichi Sankyo Co., Ltd., 2010.

24) Voltaren Tape Interview form, 4th ed., Novartis Pharma K. K., 2007.

25) Voltaren Tablets Interview form, 10th ed., Novartis Pharma K. K., 2010.
26) Mohrus Pap Interview form, 11th ed., Hisamitsu Pharmaceutical Co., Inc., 2010.

27) Menamin SR Capsule Interview form, 1st ed., sanofi-aventis K. K., 2008.

28) Saito H., Mori M., Nemoto M., Pharmacometrics, 76, 43-50 (2009).

29) Smith G. C. S., Pharmacol. Rev., 50, 35-58 (1998) .

30) Momma K., Takeuchi H., Prostaglandins, 26, 631-643 (1983).

31) Momma K., Hagiwara H., Konishi T., Prostaglandins, 28, 527-536 (1984).

32) Vickers C. F., Arch. Dermatol., 88, 20-23 (1963).

33) Guy R. H., Hadgraft J., Pharm. Res., 2, 206211 (1985).

34) Guy R. H., Hadgraft J., Int. J. Pharm., 82, R1-R6 (1992).

35) Ohtani M., Matsumoto M., Yamamura Y., Sugiura M., Uchino K., Etoh T., Jpn. J. Dermatol., 120, 37-43 (2010).

36) Imokawa G., Abe A., Jin K., Higaki Y., Kawashima M., Hidano A., J. Invest. Dermatol., 96, 523-526 (1991).

37) Levin J., Maibach H., J. Control. Release, 103, 291-299 (2005).

38) Hata M., Tokura Y., Takigawa M., Sato M., Shioya Y., Fujikura Y., Imokawa G., Lab. Invest., 82, 1451-1461 (2002).

39) Lotte C., Rougier A., Wilson D. R., Maibach H. I., Arch. Dermatol. Res., 279, 351-356 (1987). 